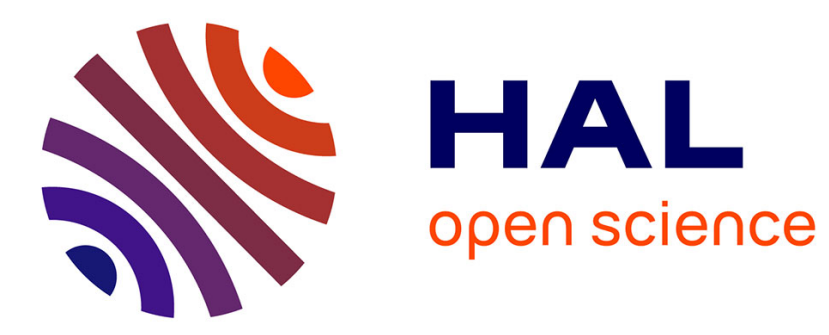

\title{
Earthquake source properties of a shallow induced seismic sequence in SE Brazil
}

Hans Agurto-Detzel, Marcelo Bianchi, Germán Prieto, Marcelo Assumpçao

\section{To cite this version:}

Hans Agurto-Detzel, Marcelo Bianchi, Germán Prieto, Marcelo Assumpçao. Earthquake source properties of a shallow induced seismic sequence in SE Brazil. Journal of Geophysical Research: Solid Earth, 2017, 122 (4), pp.2784 - 2797. 10.1002/2016JB013623 . hal-01853143

\section{HAL Id: hal-01853143 \\ https://hal.science/hal-01853143}

Submitted on 1 Nov 2021

HAL is a multi-disciplinary open access archive for the deposit and dissemination of scientific research documents, whether they are published or not. The documents may come from teaching and research institutions in France or abroad, or from public or private research centers.
L'archive ouverte pluridisciplinaire HAL, est destinée au dépôt et à la diffusion de documents scientifiques de niveau recherche, publiés ou non, émanant des établissements d'enseignement et de recherche français ou étrangers, des laboratoires publics ou privés.

$$
\text { Copyright }
$$




\section{Journal of Geophysical Research: Solid Earth}

\section{RESEARCH ARTICLE \\ 10.1002/2016JB013623 \\ Earthquake source properties of a shallow induced seismic sequence in SE Brazil}

Key Points:

- We retrieve earthquake source properties from a cluster of induced shallow $M<2$ events using a multiple empirical Green's functions method

- Considering associated uncertainties, we find low absolute stress drops

$(<1 \mathrm{MPa})$ and increase of stress drop with seismic moment

- We explain our observations as due to repeated rupture on a fault patch at shallow depth, following continuous inflow of water

Supporting Information:

- Supporting Information S1

Correspondence to:

H. Agurto-Detzel,

h.agurto.detzel@gmail.com

\section{Citation:}

Agurto-Detzel, H., M. Bianchi, G. A.

Prieto, and M. Assumpção (2017),

Earthquake source properties of a

shallow induced seismic sequence in SE

Brazil, J. Geophys. Res. Solid Earth, 122,

2784-2797, doi:10.1002/2016JB013623.

Received 6 OCT 2016

Accepted 27 FEB 2017

Accepted article online 28 FEB 2017

Published online 1 APR 2017

Corrected 15 APR 2017

This article was corrected on 15 APR 2017. See the end of the full text for details.

C2017. American Geophysical Union All Rights Reserved.

\author{
Hans Agurto-Detzel ${ }^{1}{ }^{2}$, , Marcelo Bianchi $^{1}$, Germán A. Prieto ${ }^{3}\left(\mathbb{D}\right.$, and Marcelo Assumpção ${ }^{1}$ \\ ${ }^{1}$ Institute of Astronomy, Geophysics and Atmospheric Sciences, University of São Paulo, São Paulo, Brazil, ${ }^{2}$ Now at \\ Université Côte d'Azur, IRD, CNRS, OCA, Géoazur, France, ${ }^{3}$ Departamento de Geociencias, Universidad Nacional de \\ Colombia, Bogota, Colombia
}

Abstract We study source parameters of a cluster of 21 very shallow ( $<1 \mathrm{~km}$ depth) small-magnitude $\left(M_{w}<2\right)$ earthquakes induced by percolation of water by gravity in SE Brazil. Using a multiple empirical Green's functions (meGf) approach, we estimate seismic moments, corner frequencies, and static stress drops of these events by inversion of their spectral ratios. For the studied magnitude range $\left(-0.3<M_{w}<1.9\right)$, we found an increase of stress drop with seismic moment. We assess associated uncertainties by considering different signal time windows and by performing a jackknife resampling of the spectral ratios. We also calculate seismic moments by full waveform inversion to independently validate our moments from spectral analysis. We propose repeated rupture on a fault patch at shallow depth, following continuous inflow of water, as the cause for the observed low absolute stress drop values $(<1 \mathrm{MPa})$ and earthquake size dependency. To our knowledge, no other study on earthquake source properties of shallow events induced by water injection with no added pressure is available in the literature. Our study suggests that source parameter characterization may provide additional information of induced seismicity by hydraulic stimulation.

\section{Introduction}

The estimation of source properties such as stress drop or radiated seismic energy for small-magnitude $(M<3)$ earthquakes has proved to be a difficult task in earthquake seismology [e.g., Ide and Beroza, 2001; Abercrombie, 2015; Kwiatek and Ben-Zion, 2013, 2016]. The main challenges arise from the lack of suitable data with a good signal-to-noise ratio, high sampling rates, and enough bandwidth content. One of the ongoing debates in seismology concerns the universality of scaling relations as a function of earthquake size, that is, whether stress drop is constant over a wide magnitude range of crustal seismicity [e.g., Abercrombie, 1995; Mayeda and Walter, 1996; Prieto et al., 2004; Abercrombie and Rice, 2005; Allmann and Shearer, 2009]. Some of the current controversy about scaling relations is in the magnitude range $M<3-4$, where highquality recording, path propagation corrections, and bandwidth limitations are difficult to account for [Abercrombie, 1995; Ide and Beroza, 2001; Garcia-Aristizabal et al., 2016].

Between 2004 and 2010, a small-magnitude induced seismic sequence occurred nearby the town of Bebedouro, located within the intracratonic Paraná basin in SE Brazil (Figure 1). In 2003, groundwater wells were drilled in the area for farming irrigation, the deepest well down to $200 \mathrm{~m}$ depth; and later on, in early 2004, small seismic activity began to be felt by the local population. The seismicity continued for years in the form of earthquake swarms, showing a strong temporal anticorrelation with periods of water pumping [Assumpção et al., 2010]. Most of the events had magnitudes $M<2$, but in March 2005 the most intense sequence produced events up to $m_{R}=2.9\left(m_{R}\right.$ scale is used for regional earthquakes in Brazil and it is equivalent to the $\mathrm{mb}$ magnitude scale [Assumpção, 1983]). The cause of the seismicity was determined to be the opening of the water wells and subsequent connection of a free upper aquifer with a confined lower aquifer [Assumpção et al., 2010; Dicelis et al., 2013]. This connection allowed the infiltration by gravity of water from the surface aquifer to the previously confined aquifer, inducing pore pressure increases within the lower aquifer (confined fractured basalt) and generating the small-magnitude seismicity. Although induced seismicity due to water injection/extraction at high pressures is quite common (e.g., by hydraulic fracturing, fluid injection, fluid extraction, mining, or exploiting of confined aquifers [see Rubinstein and Mahani, 2015, and references therein]), cases of shallow seismic events related solely to the opening of water wells and percolation of water by gravity are extremely rare, hence the unusual nature of this case. 


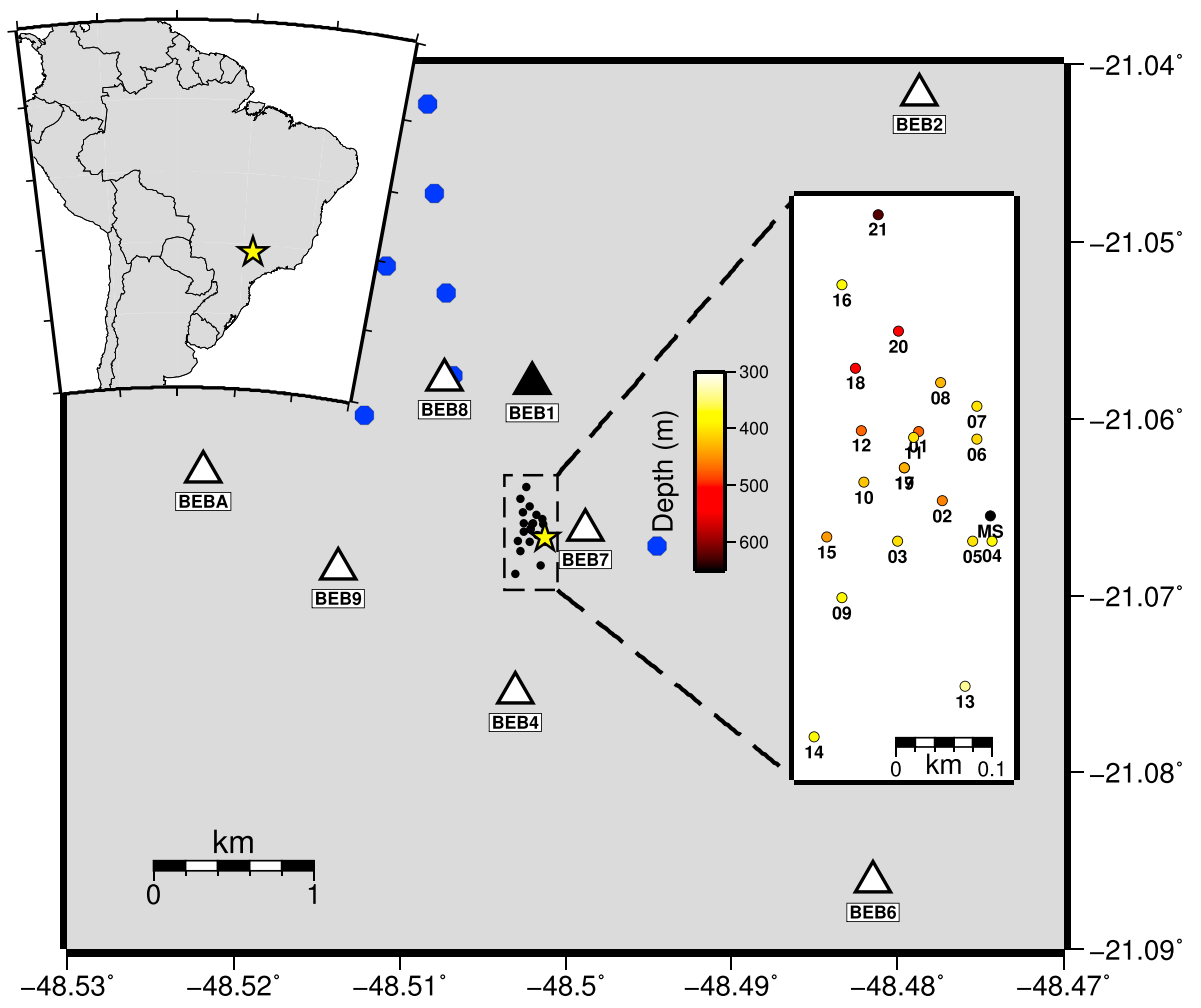

Figure 1. Distribution of events and seismic stations. Yellow star shows absolute location of M2.9 main shock (MS). Events numbered and colored by depth in zoom-in (inset). Station BEB1 in black triangle. Blue circles indicate position of water wells.

Some authors have proposed that induced earthquakes produce lower stress drops in comparison with natural earthquakes. For example, Hough [2014] observed low felt intensities for potentially induced earthquakes in central and eastern United States and interpreted them as a result of lower stress drop values relative to those of regional tectonic earthquakes. In contrast, Huang et al. [2016] compared stress drops of induced earthquakes in central United States with stress drops of tectonic earthquakes in California, finding similar values. Analyzing stress drop variations of a sequence of earthquakes induced by hydraulic stimulation at a geothermal site, Goertz-Allmann et al. [2011] found stress drops varying between 0.1 and $100 \mathrm{MPa}$ for the analyzed magnitude range ( 0 to $3 M_{w}$ ), with no obvious scaling of stress drop with magnitude. Interestingly, these authors found a strong dependence between stress drop and radial distance from the injection points, indicating that stress drops correlate well with pore pressure perturbations due to the hydraulic stimulation.

In this paper we analyze a cluster of 21 accurately located events belonging to the March 2005 Bebedouro seismic sequence. We characterize each earthquake by obtaining source properties such as seismic moment, corner frequency, static stress drop, and moment tensor derived from full waveform inversion. Our goal is to characterize the earthquake source properties of the sequence and to investigate whether there is any earthquake size or depth dependence of stress drops. We hypothesize that because of the shallow hypocenters and the physical mechanism behind the seismicity, i.e., pore pressure changes due to continuous infiltration of water at hydrostatic pressure ( 100 m water column [Assumpção et al., 2010]), the static stress drops will be of small magnitude.

\section{Materials and Methods}

After the increase in intensity and recurrence of the earthquakes in early 2005, a local seismic network composed of eight short-period stations was installed around the area to monitor the activity (Figure 1). Table S1 in the supporting information indicates the characteristics of each station. 
Table 1. Computed Source Parameters for Each Event ${ }^{a}$

\begin{tabular}{|c|c|c|c|c|c|}
\hline ID & $\mathrm{M}_{0}(\mathrm{~N} \mathrm{~m})$ & $\mathrm{fc}(\mathrm{Hz})$ & $\Delta \sigma(\mathrm{MPa})$ & $M_{w}$ & Depth (m) \\
\hline 1 & 1.49E10 (1.03E08) & $25.4(0.41)$ & $0.10(0.013)$ & 0.72 & 472 \\
\hline 2 & 3.99E08 (3.89E06) & $38.4(0.68)$ & $0.01(0.001)$ & -0.33 & 458 \\
\hline 3 & 2.43E09 (2.27E07) & $34.0(0.59)$ & $0.04(0.006)$ & 0.19 & 404 \\
\hline 4 & 4.80E09 (6.42E07) & $23.8(0.43)$ & $0.03(0.004)$ & 0.39 & 371 \\
\hline 5 & 5.37E09 (5.59E07) & $31.6(0.47)$ & $0.07(0.009)$ & 0.42 & 402 \\
\hline 6 & $6.53 \mathrm{E} 10$ (5.45E08) & $18.9(0.26)$ & $0.19(0.020)$ & 1.14 & 409 \\
\hline 7 & 8.29E09 (6.99E07) & $32.3(0.52)$ & $0.12(0.016)$ & 0.55 & 401 \\
\hline 8 & 3.46E09 (3.07E07) & $38.2(0.67)$ & $0.08(0.012)$ & 0.29 & 429 \\
\hline 9 & 2.73E10 (2.84E08) & $22.8(0.35)$ & $0.14(0.016)$ & 0.89 & 381 \\
\hline 10 & $1.68 \mathrm{E} 10$ (1.02E08) & $25.5(0.39)$ & $0.12(0.014)$ & 0.75 & 420 \\
\hline 11 & 6.99E10 (3.68E08) & $22.0(0.33)$ & $0.32(0.037)$ & 1.16 & 402 \\
\hline 12 & $3.06 \mathrm{E} 10$ (1.84E08) & $24.1(0.40)$ & $0.18(0.023)$ & 0.92 & 471 \\
\hline 13 & 3.18E09 (3.76E07) & $37.2(0.73)$ & $0.07(0.011)$ & 0.27 & 339 \\
\hline 14 & $1.08 \mathrm{E} 10(8.40 \mathrm{E} 07)$ & $26.2(0.44)$ & $0.08(0.011)$ & 0.62 & 380 \\
\hline 15 & 1.51E09 (1.46E07) & $29.9(0.55)$ & $0.02(0.002)$ & 0.05 & 445 \\
\hline 16 & 7.15E09 (1.23E08) & $28.0(0.49)$ & $0.07(0.009)$ & 0.50 & 371 \\
\hline 17 & 8.67E11 (1.91E10) & $11.4(0.18)$ & $0.55(0.059)$ & 1.89 & 433 \\
\hline 18 & 3.81E09 (7.67E07) & $34.2(0.74)$ & $0.07(0.011)$ & 0.32 & 510 \\
\hline 19 & $6.92 \mathrm{E} 11$ (1.28E10) & $13.3(0.23)$ & $0.70(0.082)$ & 1.83 & 433 \\
\hline 20 & 5.27E09 (3.79E07) & $34.0(0.58)$ & $0.09(0.012)$ & 0.42 & 544 \\
\hline 21 & $4.46 \mathrm{E} 10$ (2.82E08) & $21.8(0.35)$ & $0.20(0.024)$ & 1.03 & 622 \\
\hline
\end{tabular}

${ }^{\mathrm{a}}$ Standard deviation $(\sigma)$ from jackknife test is shown in parenthesis. The events ID number follows chronological order of occurrence. For exact origin time, please see supporting information.

Dicelis et al. [2013] selected a cluster of 19 events based on their waveform correlation occurred between 26 and 30 March 2005 and obtained highly accurate locations by waveform cross correlation. Here we take advantage of these locations and analyze the events from this cluster. The cluster also contains aftershocks of the largest quake of the whole Bebedouro sequence, a $m_{R}=2.9$ event. Unfortunately, the records of this main event are saturated, and consequently, this earthquake was not included in our analysis. Nevertheless, the catalog contains two other events within the cluster (No. 17 and 19; see Table 1), with magnitudes $M=1.9$ and $M=1.8$, respectively. The location of these two events was not computed by Dicelis et al. [2013], so we constrained it to be the mean hypocenter of the rest of the cluster events. In any case, the precise absolute location of the hypocenters is not important for our spectral analysis as long as the events are collocated and belong to the same well-defined cluster with similar waveforms. Thus, the total number of events considered in our analysis is 21 .

Because the seismic network was quickly installed and designed for simple location purposes, we found several problems in our data set concerning the application of spectral analysis (Figure 2). For instance, low signal-to-noise ratios were present in most of the stations because of the low magnitude of the events and the distance to some of the stations. In the case of the largest earthquakes, signal saturation (clipping) is observed in the closest stations and/or stations with high gain. Furthermore, some of the stations had three components and high sampling rate $(500 \mathrm{~Hz})$, while others had only one component (vertical) and a $200 \mathrm{~Hz}$ sampling rate. Finally, some of the stations also showed significant electronic noise, while some had GPS-time related issues. Due to these difficulties, we decided to perform our spectral analyses using only the best of our stations (BEB1, see Figure 1), which did not present any of the problems listed above.

In spectral analysis and estimation of source parameters, it is required to account for source radiation, propagation, and near-site effects [e.g., Shearer et al., 2006]. For small-magnitude earthquakes, one important issue to consider is the limited bandwidth due to attenuation, which limits the high-frequency content of the data. In order to tackle these issues, we adopted the method of spectral ratios, also known as multiple empirical Green's functions (meGf) method, as proposed by lde et al. [2003], in turn based on the approach followed by Hough [1997]. Several authors [Ide et al., 2003; Prieto et al., 2006; Abercrombie, 2015; Ross and Ben-Zion, 2016] have shown the usefulness and reliability of using meGf methods in the computation of earthquake source parameters. 

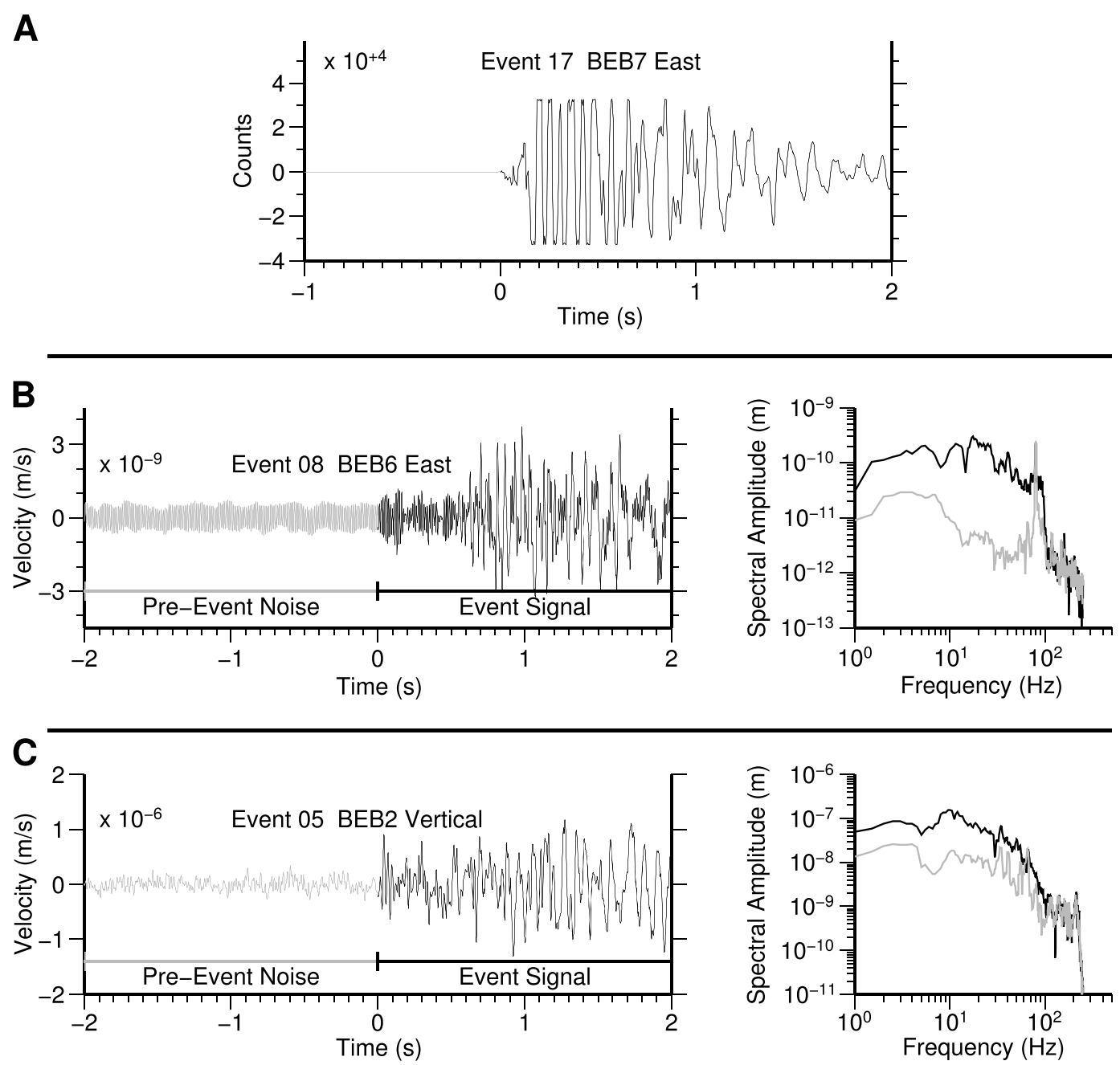

Figure 2. Examples of some of the problems commonly found in the Bebedouro data set. (a) Instrument saturation; (b) Electronic noise around $\sim 80 \mathrm{~Hz}$. (c) Low signal-to-noise ratio.

From Ide et al. [2003], the ratio between the velocity spectra of two events (events $k$ and $I$ ) is expressed as

$$
\log \dot{u}_{k}^{c}\left(f_{i}\right)-\log \dot{u}_{l}^{c}\left(f_{i}\right) \approx g\left(f_{i} ; \log M_{o k}, \frac{1}{Q^{c}}, f_{c k}^{c}\right)-g\left(f_{i} ; \log M_{o l}, \frac{1}{Q^{c}}, f_{c l}^{c}\right),
$$

where $f_{c}^{c}$ is the corner frequency of the phase $c$ ( $P$ wave or $S$ wave), $Q^{c}$ is the attenuation coefficient of either $P$ wave or $S$ wave, $M_{0}$ is the seismic moment, and $g$ is the Green's functions. If the path is common to the two events, i.e., these are colocated, and following the Boatwright spectral model [Boatwright, 1980], the righthand side of (equation (1)) can be written as

$$
\log M_{0 k}-\log M_{0 l}+\frac{1}{2} \log \frac{\left(1+\left(\frac{f_{i}}{f_{c l}^{c}}\right)^{4}\right)}{\left(1+\left(\frac{f_{i}}{f_{c k}^{c}}\right)^{4}\right)}
$$

and the unmodeled effects of attenuation (and in principle other propagation and site effects) are removed from the problem.

Thus, when there are $N$ points of frequency data for each spectrum and $M$ events, we have $N{ }^{*} M(M-1) / 2$ equations to determine $M$ seismic moments and $M$ corner frequencies. However, these equations do not supply information about the absolute values of seismic moments. We then add another equation to equalize the logarithmic average of computed seismic moments to a previously determined average seismic moment 


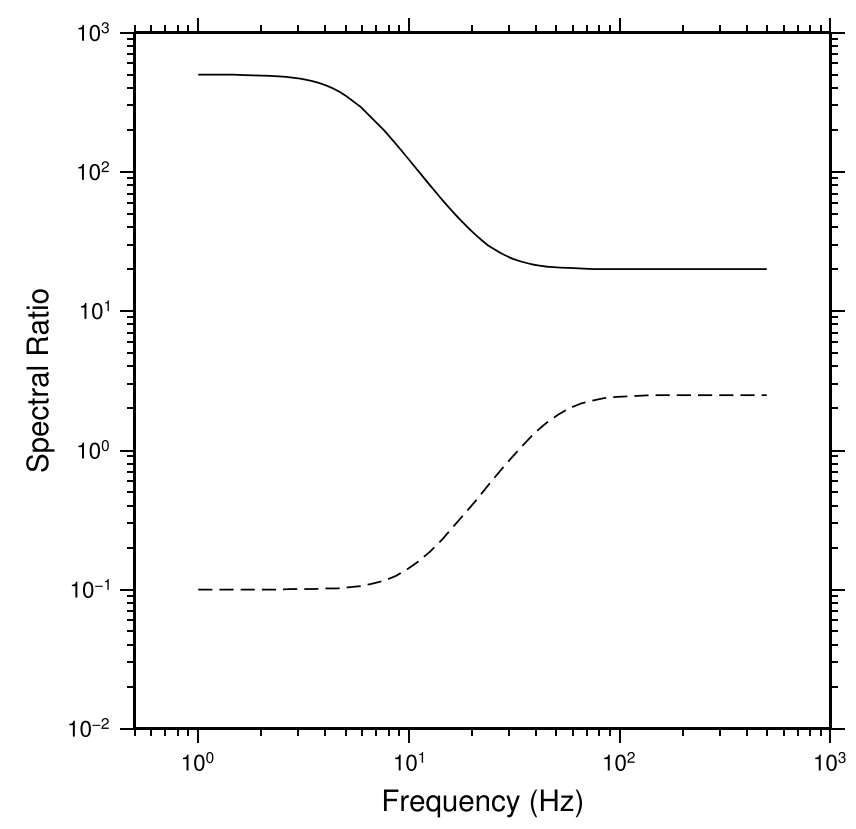

Figure 3. Idealized spectral ratios for two pairs of events according to equation (2). Solid line shows ratio for a pair of events in which the reference event (dividend) is greater than the divisor event. Dashed line shows ratio for a pair in which the reference event is smaller than divisor event. See text for details. moments we used preliminary seismic
moments calculated from the flat level of the low-frequency part of the displacement spectrum of each event by using the equation

$$
M_{0}=\frac{4 \pi \rho c^{3} r \Omega_{0}}{U_{\varphi \theta}}
$$

[Shearer, 2009] where $\rho$ is the density, $c$ is the wave velocity, $r$ is the distance source station, $\Omega$ is the long-period spectral level (low-frequency flat level), and $U_{\varphi \theta}$ is the radiation pattern that depends on the focal mechanism but it can be averaged to 0.52 for $P$ waves and 0.63 for $S$ waves. In our case we calculated spectra for the full waveform considering $P$ and $S$ waves together $(0.4 \mathrm{~s}$ window length), but as the largest amplitudes are present during the $S$ wave, we used the velocity and radiation pattern values for the $S$ wave. These preliminary moment values should be a very good approximation to the final moments because of the small epicentral distance of station BEB1, which guarantees minimal attenuation effects particularly at low frequencies.

Moment magnitudes $\left(M_{w}\right)$ were calculated from the obtained seismic moments using the equation

$$
M_{w}=2 / 3^{*}\left(\log _{10}\left(M_{0}\right)-9.1\right),
$$

([Hanks and Kanamori, 1979] $M_{0}$ in $\mathrm{N} \mathrm{m}$ ).

Finally, with the determined corner frequencies and seismic moments for each event, we can calculate static stress drops by using the equation

$$
\Delta \sigma=7 / 16 \mathrm{M}_{0}\left(2 \pi f_{c} / 2.34 \beta\right)^{3},
$$

[Eshelby, 1957; Brune, 1970] where $\beta$ is the $S$ wave velocity equivalent to $2700 \mathrm{~m} \mathrm{~s}^{-1}$ [Dicelis et al., 2013]. It is important to mention that equation (5) considers a circular rupture with constant rupture velocity proportional to $\beta$, thus assuming that all variations in corner frequency are related to variations in rupture size only.

Our processing workflow was as follows:

1. We select the events/seismograms and deconvolve the instrument response.

2. We compute the velocity and displacement spectra for each event/component (Figure 4). We used a $0.4 \mathrm{~s}$ window of data after the $P$ wave arrival, which also contains the $S$ wave arrival. A window of $0.4 \mathrm{~s}$ before 

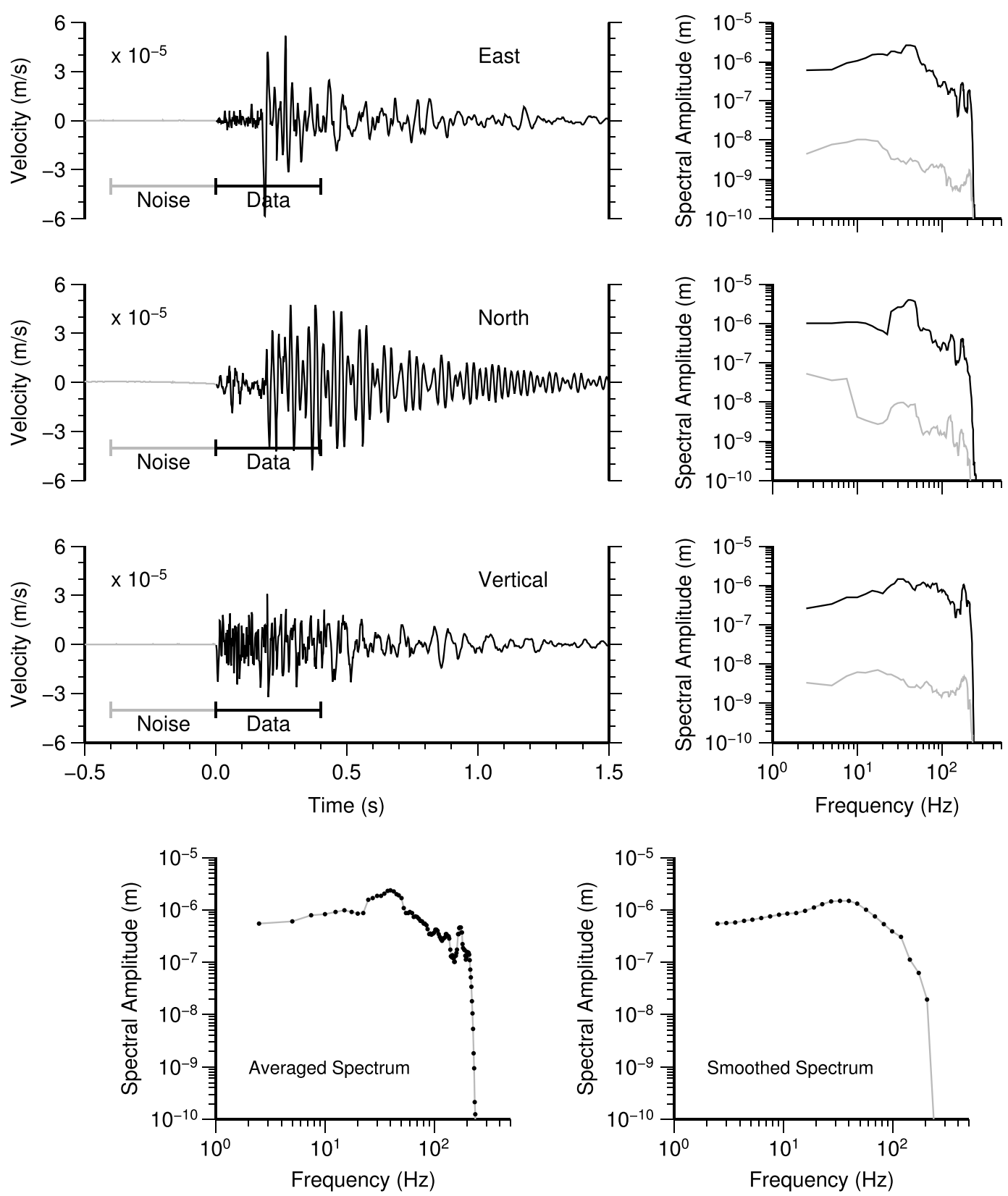

Figure 4. Example of processing for event 04 . Velocity seismograms and spectra of data (black) and noise (grey) for each component. Lower two plots show three-component averaged spectrum and smoothed spectrum.

the $P$ wave arrival was considered for a subset of preevent noise signal in order to visually inspect the suitability of the data and signal-to-noise ratios. Note that signal-to-noise is very high up to $250 \mathrm{~Hz}$ (our Nyquist frequency), which is difficult to obtain for surface sensors [Abercrombie, 2014, 2015]. Spectra were computed using the spectral estimation library developed by Prieto et al. [2009].

3. We calculate the logarithmic mean of the three components to obtain an averaged spectrum per event.

4. We smooth the averaged spectra (Figures 4 and 5) by a moving average and resample the frequency vector using an octave scale. This step produces a smoothed spectrum with sampling frequencies equally spaced in the logarithmic space. This is done so the nonlinear inversion computes ratios with sampling points equally distributed in the frequency domain, avoiding giving extra weight to the overly sampled high frequencies of the nonsmoothed spectra.

5. We compute the preliminary seismic moments from displacement spectra using equation (3). 


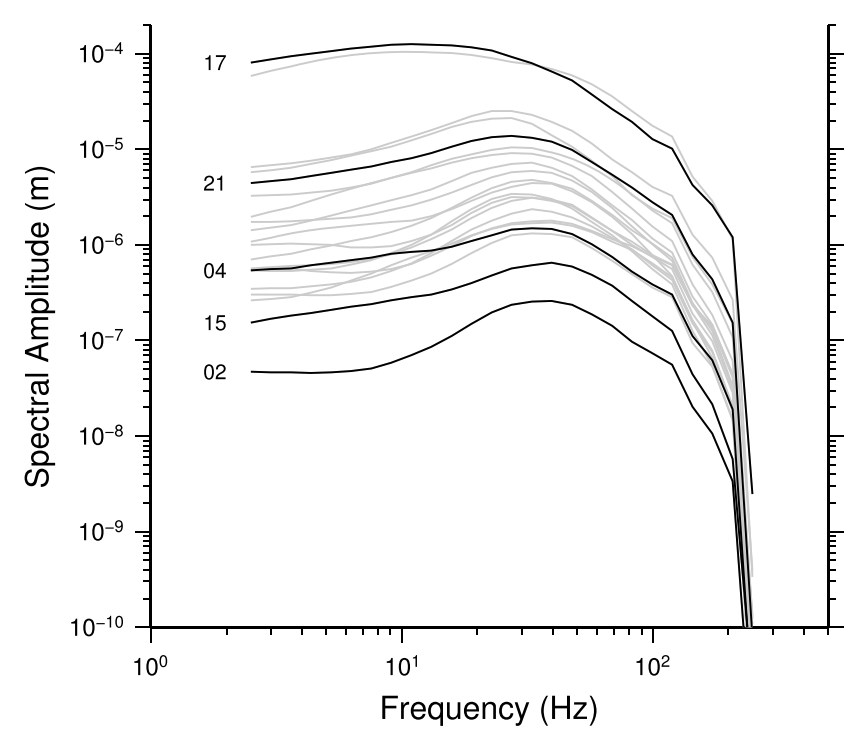

Figure 5. Smoothed velocity spectra for all events. Some events are numbered and highlighted in black for better display.

6. We compute the spectral ratios between all pairs of events.

7. We perform the simultaneous nonlinear inversion of spectral ratios and preliminary average moment to obtain corner frequencies and seismic moments of all events using equation (2). Each event inversion starts from an extreme case scenario in which the initial value of seismic moment is constrained to be the logarithmic average of all preliminary seismic moments, and the initial value of corner frequency is equalized to $25 \mathrm{~Hz}$. We tested different scenarios (varying initial corner frequencies between 10 and $80 \mathrm{~Hz}$ ) with similar results (Figure S6).
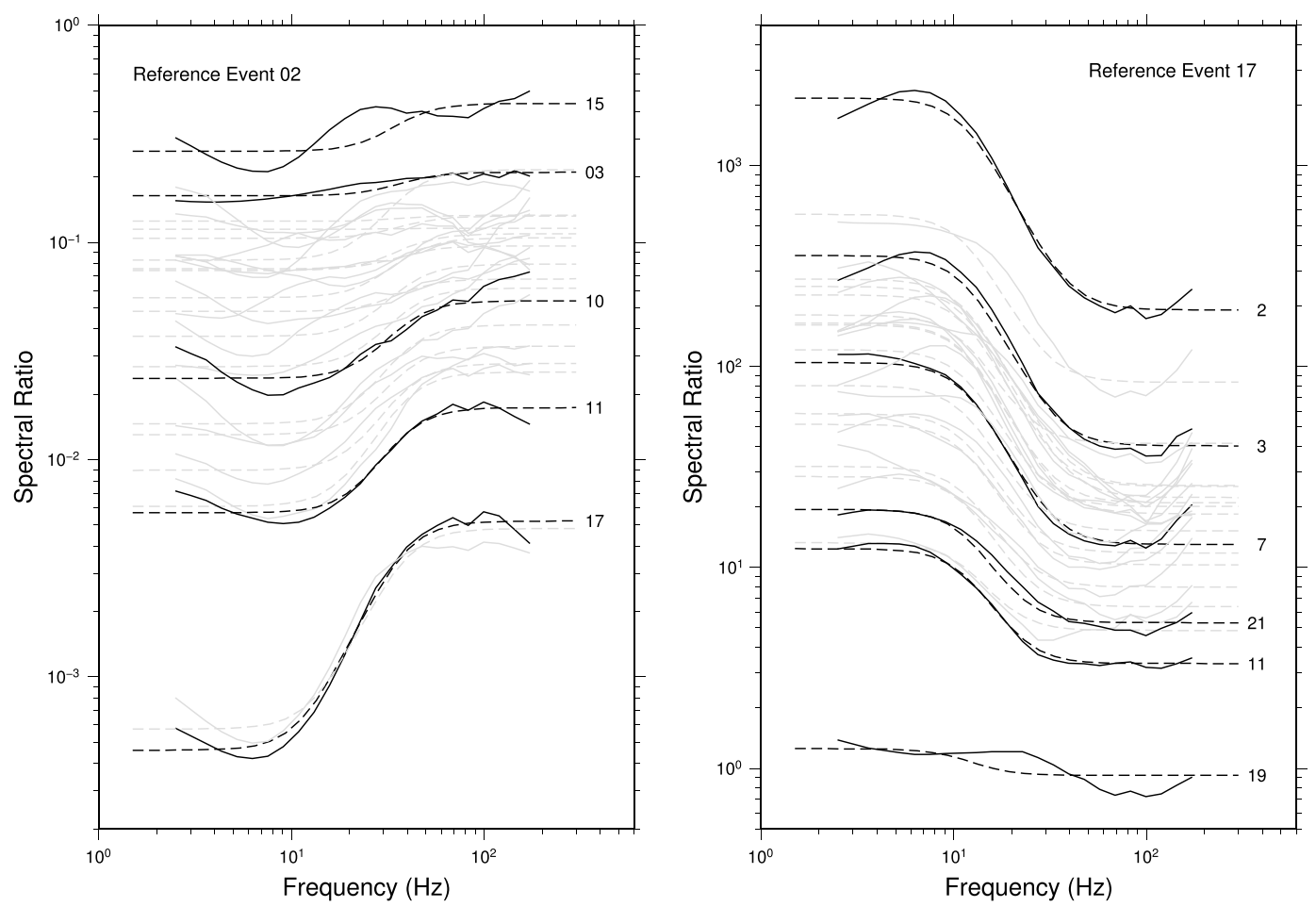

Figure 6. Example of calculated spectral ratios for reference event (left) 02 and (right) 17. Observed ratios are in solid line, and modeled ratios are in dashed line. Some events are highlighted in black for better display. 

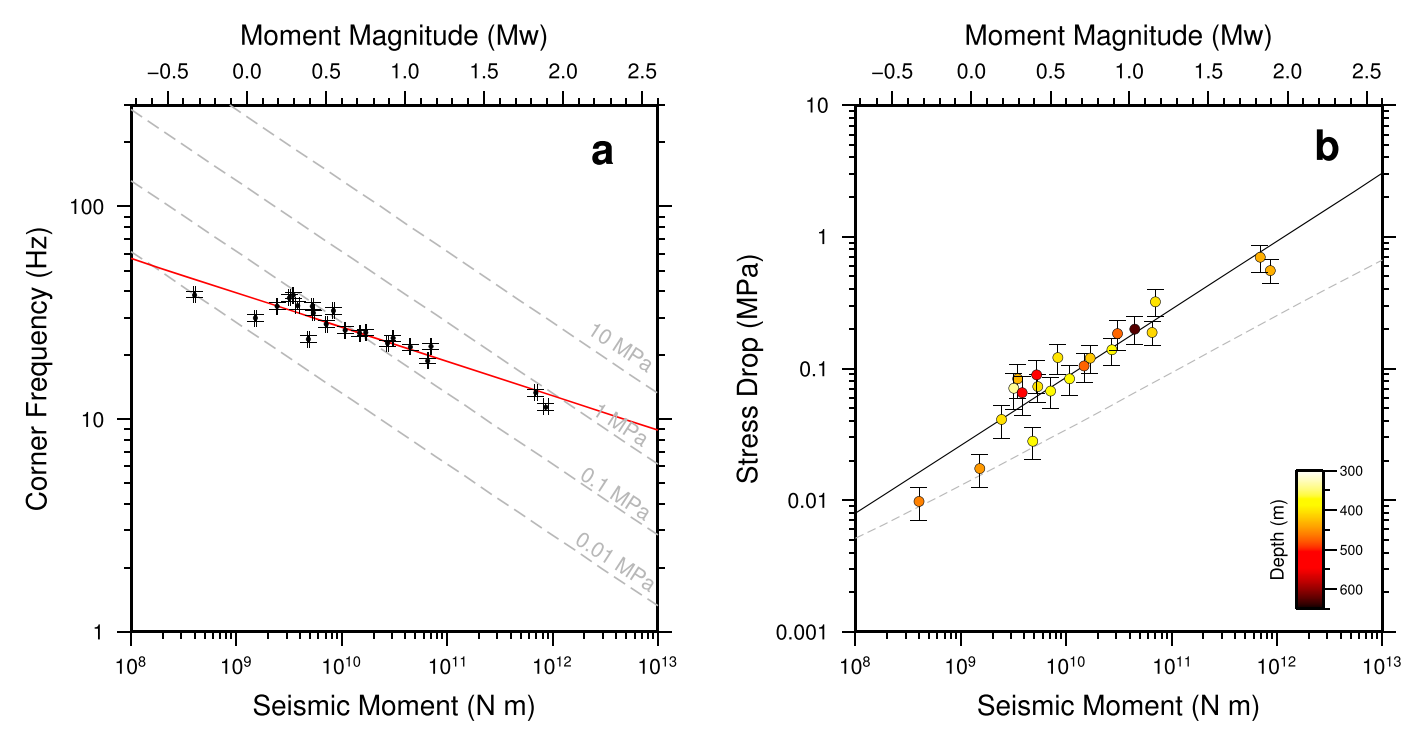

Figure 7. Calculated source parameters. (a) Corner frequency against seismic moment. Red line shows best fitted straight line. Constant stress drops depicted by grey dashed lines. (b) Stress drop against seismic moment. Events colored by depth. Solid black line shows best fitted straight line; grey dashed line shows relation found by Drouet et al. [2011]. In both plots error bars depict $2 \sigma$ from values obtained in jackknife resampling.

\section{Results}

\subsection{Spectral Ratios}

We obtained a good fit between modeled and observed spectral ratios for all pairs of events (Figure 6). The adjustment is particularly good for pairs of events with larger magnitude difference, while the fit tends to decrease for pairs of events with similar size (ratio close to 1), with spectral ratios showing a more complex shape. The calculated values for corner frequencies, seismic moments, and static stress drops can be seen in Table 1 and Figure 7. Seismic moments vary from $3.99 \times 10^{8}$ to $8.67 \times 10^{11} \mathrm{~N} \mathrm{~m}\left(-0.3\right.$ to $\left.1.9 \mathrm{M}_{w}\right)$, while corner frequencies range between 11 and $38 \mathrm{~Hz}$. Static stress drops vary between 0.01 and $0.7 \mathrm{MPa}$, showing a positive correlation with earthquake moment but no clear depth dependence.

In order to estimate uncertainties related to our calculations, we performed a jackknife type of test [e.g., Prieto et al., 2007] in which we resampled our set of spectral ratios randomly removing $20 \%$ of them each time and then proceeding with the inversion. We run this test 1000 times and then calculated the standard deviation $(\sigma)$ for the obtained corner frequencies, seismic moments, and stress drops for each event. All populations of calculated values for each event showed a normal distribution. The estimated uncertainties are shown in Table 1 and in Figure 7 as error bars indicating $2 \sigma$.

\subsection{Moment Tensors}

We computed moment tensors for 12 of our 21 events. For this step we used the software ISOLA [Sokos and Zahradnik, 2008; Sokos and Zahradník, 2013] which retrieves moment tensors from full wavefield inversions of local and regional waveforms. As a reference velocity model we used the minimum 1-D velocity model [Kissling et al., 1994] obtained by Dicelis et al. [2013]. Inversions were performed in the frequency band 1.4-2.6 Hz. Lower frequencies did not present enough amplitude content, and higher frequencies resulted in poorly fitted waveforms because of the simplicity of the velocity model used. Also, because of the limited frequency bandwidth we could only retrieve moment tensors for events with $M_{w}>0.5$. The results of the inversions are shown in Figure 8 and in the supporting information.

\section{Discussion and Conclusion}

Our stress drop estimates show large variability, varying over almost 2 orders of magnitude, despite the fact that we processed only 21 events with moments spanning 4 orders of magnitude. A large variability of stress drops, over 2 or 3 orders of magnitude, is common for a large set of events [e.g., Abercrombie, 1995; Allmann 


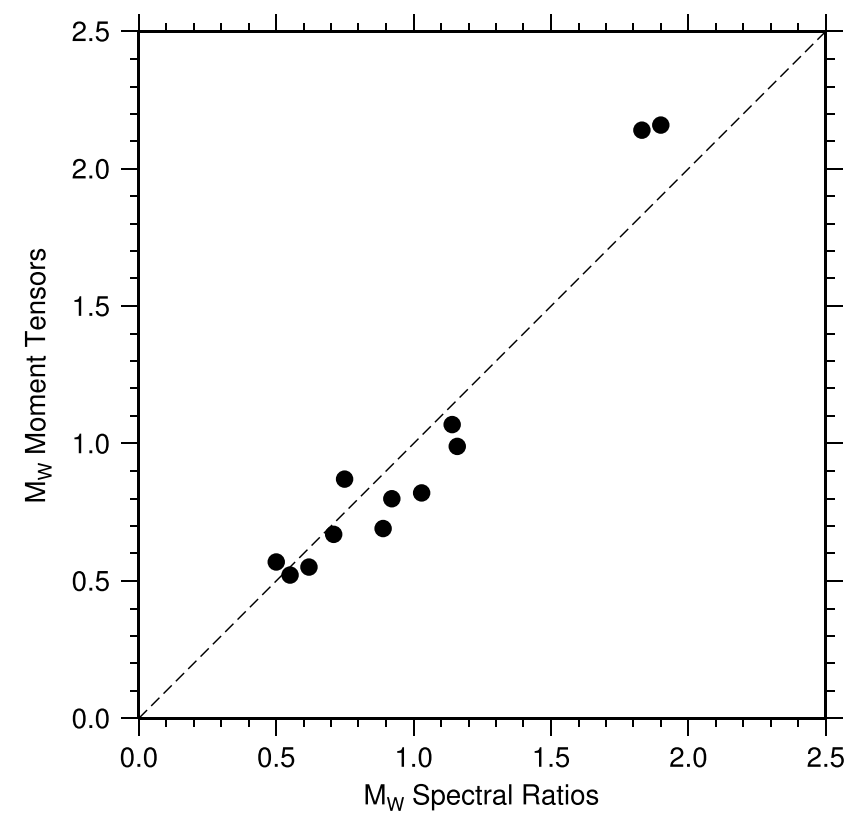

Figure 8. Comparison between moment magnitudes obtained from spectral ratios and moment tensor inversions. Dashed line indicates 1:1 relation. and Shearer, 2009; Baltay et al., 2011]. Some studies [e.g., Baltay et al., 2011] suggest that large populations of stress drops are lognormally distributed. Figure 9 shows a histogram with the log distribution of our stress drop values, which surprisingly seems to fit well a normal distribution, despite the observed dependency of stress drop with moment and the small number of processed events. In our case, though, the good fit with a normal distribution can be due to our earthquakes concentrating around $M_{w} \sim 0.7$, equivalent to the mean of $\Delta \sigma \sim 0.1 \mathrm{MPa}$, with few events on the edges of the magnitude range (Figure $7 b$ ).

For the studied magnitude range $\left(M_{w}\right.$ -0.3 to 1.9 ), we obtained static stress drops between 0.01 and $0.7 \mathrm{MPa}$, which in general correspond to low values in comparison with what is reported in the literature, usually ranging from 0.1

to $100 \mathrm{MPa}$ [e.g., Abercrombie, 1995; Allmann and Shearer, 2009; Baltay et al., 2011]. It is important to mention, however, that the estimation of stress drops from corner frequencies requires several assumptions regarding the source model, such as the shape of the rupture area, the average rupture velocity, and effects of directivity, which makes it difficult to compare different studies as these assumptions often vary.

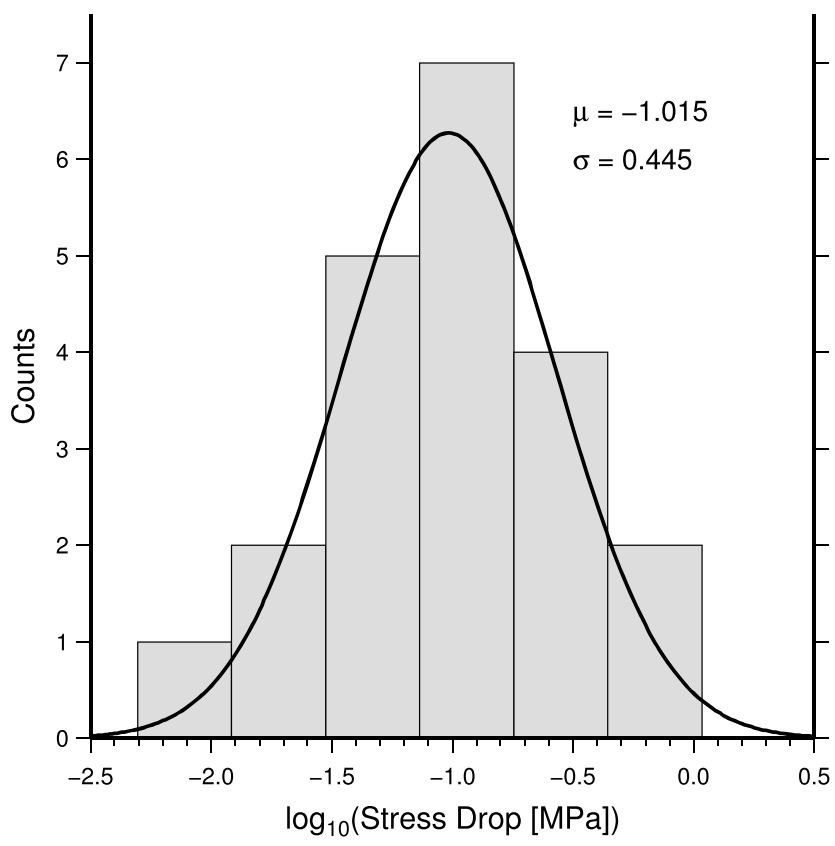

Figure 9. Histogram showing the logarithmic distribution of the calculated stress drops. Mean $(\mu)$ and standard deviation $(\sigma)$ values are shown, as well as the probability density function of a normal distribution (black line).
To our knowledge, no other study on stress drops of shallow induced earthquakes due to percolation of water by gravity exists in the literature. Previous studies of stress drop estimates for induced seismicity cover earthquakes due to injection of water at high pressures [e.g., Goertz-Allmann et al., 2011; Huang et al., 2016] and show stress drops varying between 0.1 and $100 \mathrm{MPa}$. Huang et al. [2016] argued that, for central United States, no clear difference exists between stress drops of induced events and tectonic events.

An interesting case of seismicity induced by deep injection of wastewater occurred in the Raton Basin, southern Colorado. There, seismicity is ongoing since 2001, ranging between 2 and $8 \mathrm{~km}$ depth, and producing a $M_{w} 5.3$ main shock in 2011 [Rubinstein et al., 2014; Barnhart et al., 2014]. Interestingly, most of the wastewater wells in the Raton Basin dispose water under gravity feed. Unfortunately, there are no estimations of stress drops for 
this sequence, although in relation to the largest earthquake, Barnhart et al. [2014] suggested that the wastewater disposal may have triggered a low stress drop event, considering that the rupture length of the 2011 main shock (estimated from the aftershock locations) was unexpectedly long for a $M_{w} 5.3$ earthquake.

Our absolute low stress drop values may be explained by the combination of two effects. First, considering the low confining pressures present at our hypocentral depths $(<1 \mathrm{~km})$, on a fault governed by rate and state friction where stress drop is proportional to the normal stress, it is expected to observe low stress drops at these very shallow depths [e.g., Gu and Wong, 1991; He et al., 2003; Rubin and Ampuero, 2005]. Second, we hypothesize that all the earthquakes were repeatedly breaking the same fault patch (see below). If so, continuous inflow of water in the same part of the fracture would favor additional changes of effective stresses after the initial earthquakes in 2004, producing subsequent low stress drop ruptures. Consequently, the low stress drop values we calculated for our 2005 cluster could be due to the small remaining stresses after the initial ruptures of the first active period in early 2004, following the continuous inflow of water.

We found a positive correlation between stress drop and earthquake size within the moment range $10^{8}$ and $10^{12} \mathrm{~N} \mathrm{~m}$. The equation for a best fitted straight line relating static stress drop and seismic moment (Figure 7b) is $\Delta \sigma=10^{\wedge}\left(0.516 \times \log _{10}\left(\mathrm{M}_{0}\right)-6.231\right)$. This equation is similar in slope to the relation proposed by Drouet et al. [2011], which also found a positive correlation between stress drop and seismic moment for a seismic sequence in the French West Indies, although their analyzed events ranged in magnitude from 2 to $6 M_{w}$.

Some other studies have also suggested a nonsimilar source behavior of clustered microearthquakes. For example, Lin et al. [2016] found constant source duration (and so rupture size) independent of moment for closely located events within the magnitude range 0.3 to 2.0. This violates the scaling of source duration and moment implied by self-similarity of earthquakes [e.g., Duputel et al., 2013]. Likewise, Lengliné et al. [2014] found that tightly clustered repeating earthquakes at a geothermal site in France presented similar corner frequencies and therefore similar rupture sizes despite difference in moment of up to a factor of 300 , implying a proportional great variability in stress drop. They interpreted this large variation as result of rapid changes in local conditions due to changes in fluid pressure reducing the normal stress at the interface of the asperity. Similarly, our results show events closely located with high waveform similarity [Dicelis et al., 2013], a relatively large stress drop variability of a factor of 70, and dependency of stress drop with moment. It could be, then, that our events despite having different moment are rupturing the same seismogenic patch with a defined size and thus producing stress drops with large variability. This variation in stress drop scales with seismic moment, and we hypothesize this is due to temporal changes of the effective stress at the patch interface caused by variations in fluid pressure due to the infiltration of water.

The large similarity between all $P$ wave and $S$ wave arrivals (waveform correlation) and the location of the hypocenters fitting one fault plane [Dicelis et al., 2013] is consistent with all events in the cluster corresponding to slip in the same fault patch with the same focal mechanism. In addition, the effects of percolation of water from the upper aquifer, as well as continuous water infiltration during the rainy season, are consistent with the hypothesis of a repeatedly slipping low-friction patch.

The focal mechanisms from moment tensor inversions shown in the supporting information (Figure S1) have large variability of fault plane geometry, which is not consistent with a common fault patch. However, as we explain below, these focal mechanisms are not very reliable and should be considered with caution as they were obtained using only two or three stations with poor azimuthal coverage and not always optimal signal-to-noise ratios. The moment tensor inversions were meant to retrieve independent estimates of the seismic moment only.

The main event in the March 2005 sequence was a $m_{R}=2.9$ event [Assumpção et al., 2010]. For SE Brazil, it has been found the relation $M_{w}=m_{R}-0.4 \pm 0.1$ [Drouet and Assumpção, 2013; Agurto-Detzel et al., 2015]. Hence, if we consider the main event to have $M_{w}=2.5$, and extrapolating the relation found for corner frequency versus seismic moment (Figure 7a), we obtain a $f c=9.4 \mathrm{~Hz}$ for this event. We can then calculate the source size, which is related to the spectral corner frequency as $r=\kappa^{*}(\beta / f c)$, with the coefficient $\kappa=0.37$ [Brune, 1970; Hanks and Wyss, 1972]. Thus, considering $\beta=2700 \mathrm{~m} \mathrm{~s}^{-1}$ we obtain a source radius $r=106 \mathrm{~m}$, assuming a circular fault. From the hypocentral distribution of the cluster events we observe a rupture length between 300 (minimum) and $500 \mathrm{~m}$ (maximum). Our radius of $106 \mathrm{~m}$ (diameter of $212 \mathrm{~m}$ ) is somehow shorter of the observed rupture length, but still within the expected variability found in relations involving source 
parameters and rupture dimensions [e.g., Nuttli, 1983; Wells and Coppersmith, 1994]. In a similar manner to the findings of Barnhart et al. [2014], the somehow long rupture length we estimate from the aftershock distribution indicates a low stress drop event. Likewise, the shorter than expected rupture length we estimate from spectral analysis also supports the idea of a common fault patch shared by all the events as suggested above (i.e., rupture size independent of earthquake size).

The moment magnitudes calculated from moment tensor inversions correlate well with the magnitudes from the spectral ratio analysis (Figure 8). If any, the magnitudes from moment tensors are slightly lower than the magnitudes from spectral ratios. This can be explained by the way the magnitudes are computed in the moment tensor inversion, in which the final seismic moment is proportional to the fitting between observed and synthetic seismograms [Zahradník and Gallovič, 2010]. Accordingly, because we could only use two or three stations per event, and the resulting waveform fit was not optimal, the calculated seismic moments from moment tensor inversions might be slightly underestimated. There were, however, two events (the two largest of the sequence) for which the calculated moment from waveform inversion was noticeably higher than the moment calculated from spectral ratios. This can be explained because we inverted the moment tensors for only one source located at the hypocenter, and, as mentioned above, the hypocenters of these two events were not as well resolved as for the rest of the events. So it might be that in reality these two events were located slightly closer to the stations (e.g., shallower hypocenters), and hence the seismic moment from the waveform inversion is overestimated assuming a somewhat wrong location (i.e., larger hypocentral distances).

The idea behind computing moment tensors was mainly to calculate moment magnitudes using an independent method that could help validating our magnitudes from spectral analysis. Because of the problems found in our data set, we could only use two or three stations for the waveform inversion. The calculated magnitudes should be a good approximation to the real magnitudes, but the obtained focal mechanisms are not well resolved and so we prefer not to discuss them in the main section (they are shown in the supporting information section).

The choice of the spectral model could potentially lead to biases in the calculation of earthquake source parameters. We used the Boatwright spectral model [Boatwright, 1980], instead of the Brune model [Brune, 1970], because it presents sharper corner frequencies in the shape of the spectral ratios [Abercrombie, 2015; Huang et al., 2016], thus facilitating the accurate estimation of this parameter. Furthermore, using the spectral ratio method, Huang et al. [2016] argued that the Boatwright model leads to smaller uncertainties in stress drop estimates. Other studies [e.g., Baltay et al., 2011; Abercrombie, 2014, 2015] found no systematic difference between the results obtained by using either of the spectral models. Huang et al. [2016] found that the Boatwright model leads to slightly lower corner frequencies (and thus, lower stress drops) than the Brune model, although they notice that the discrepancy might be due to bandwidth limitations in their data set.

Our data have a large bandwidth, with high signal-to-noise ratio up to $250 \mathrm{~Hz}$. Our estimated corner frequencies are quite low compared to other crustal events of similar size [e.g., Abercrombie, 1995, 2014], but given the high signal-to-noise ratios, we believe that our data should be sensitive to larger corner frequencies. Abercrombie [2015] argued that if the corner frequencies are within a factor of 3 of the maximum frequency of the signal, they may be underestimated. In our case, with maximum usable frequency of $250 \mathrm{~Hz}$, only corner frequencies above $\sim 80 \mathrm{~Hz}$ may suffer from bandwidth limitations, with our calculated corner frequencies $<40 \mathrm{~Hz}$ in all cases.

The small uncertainties we obtained from our jackknife resampling test demonstrate the stability of the inversion of spectral ratios (see errors bars in Figure 7 and Table 1). In particular, the calculated seismic moments proved to be very stable, with standard deviations less than $1 \%$ of the calculated moments. The somehow greater uncertainties seen for stress drops can be explained by the cubic factor applied to the corner frequencies in equation (5) [Cotton et al., 2013; Kane et al., 2011]. Nonetheless, the uncertainties in stress drop are still very small and stable, not affecting the tendency and positive correlation found between stress drop and seismic moment. We also performed jackknife tests removing $10 \%, 15 \%$, and $30 \%$ of the sampled ratios, finding similar uncertainties and proving the stability of the inversions (see Figure S7). It is important to highlight, though, that our estimation of uncertainties using a jackknife method provides a measure of the robustness of the inversion procedure only and thus an indirect measure of the likelihood associated with the fitted best model. 

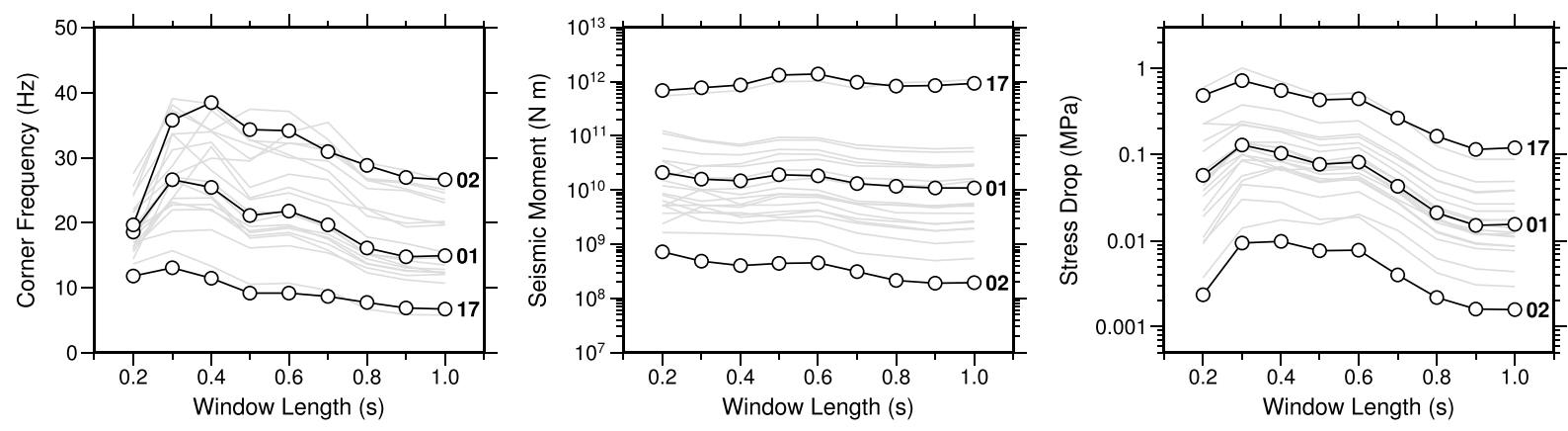

Figure 10. Variation of calculated (left) corner frequency, (middle) seismic moment, and (right) stress drop for different window lengths for each event (grey lines). Events 01,02 , and 17 are highlighted in black for better display.

Another source of uncertainty might be the selection of the window length for the processed data. We selected windows of $0.4 \mathrm{~s}$ of data based on a visual inspection of the records, considering S-P times and ensuring both $P$ wave and $S$ wave trends were contained in the window but excluding surface waves and the coda of the event. Because of the small epicentral distance of BEB1 station, and subsequent short S-P times, we could not consider $P$ and $S$ windows separately as the windows would be too small with too little bandwidth content for the correct computation of frequency spectra. Additionally, we performed a series of tests considering different window sizes to investigate the variability of our results depending on this variable (Figure 10). We can see that while seismic moments seem to be relatively independent of the considered window size, there is a larger variation of the computed corner frequencies and, therefore, of the stress drop values. Nonetheless, a plateau of values is observed for window sizes between 0.3 and $0.6 \mathrm{~s}$, which include both $P$ and $S$ waves but exclude most of the surface waves. Accordingly, our selection of window length of $0.4 \mathrm{~s}$ seems to be appropriate.

Radiation pattern and directivity effects may also bias our estimated stress drops [e.g., Zhan et al., 2014]. In our study we analyzed data from a single station (BEB1) because of its high $\mathrm{S} / \mathrm{N}$ ratio over a wide frequency range and suitable recording of the largest number of events. We analyzed alternatively two other stations that had a significant number of overlapping events (BEB2 and BEB4; Figure S8). The comparison of the results of each individual station shows that average variability of corner frequency estimates could be of the order of $30 \%$, similar to uncertainties calculated in other studies [e.g., Prieto et al., 2007], suggesting that potential bias is not as large in this particular case. We also noticed that low $\mathrm{S} / \mathrm{N}$ ratios at station $\mathrm{BEB} 2$, particularly at high frequencies, prevent the accurate estimation of corner frequencies larger than $20 \mathrm{~Hz}$, highlighting the need for highquality recording at a wide frequency band to avoid underestimating stress drops for small earthquakes. Furthermore, the main features found in our study, such as the absolute low values of stress drop and the increase of stress drop with seismic moment, are retrieved both when we consider an average value from all three stations together and when we consider an individual analysis of each station separately.

Lastly, one important point to consider is the suitability and limitations of our data set to perform spectral analysis. We found several problems in our waveforms due to poor sampling, low signal-to-noise ratios, and GPS-time related problems. Furthermore, our stations were installed over the surface, which greatly contributes to noise, attenuation, and site effects. On the other hand, we benefited from the small epicentral distance of station BEB1, which granted a good signal-to-noise ratio over high frequencies and low attenuation effects. Ideally, studies involving spectral analysis of small-magnitude earthquakes should be carried out using borehole three-component seismometers with high sampling rates. Also, any general conclusion regarding the validity of earthquake scaling relations should be based on the homogeneous analysis of a wide range of magnitudes, which unfortunately we lacked. Furthermore, because our seismic network configuration was not kept fixed during the whole extent of the seismic activity, we could not consider a larger period of study, which would have allowed us to study spatiotemporal relations between earthquake source parameters and the position of water wells and periods of rain and water pumping. In any case, no robust spatiotemporal correlation is observed for the short period of our study (see Figures S4 and S5). We encourage that future deployments of seismic stations for the monitoring of small-magnitude earthquake sequences in the region should contemplate not only the study of earthquake locations but also of source properties and spectral analysis, ensuring the instrumental capabilities described above. 


\section{Acknowledgments}

We thank Editor Yehuda Ben-Zion, Olivier Lengliné, and an anonymous reviewer for their comments and suggestions. H.A. acknowledges support from CAPES and Sao Paulo Research Foundation FAPESP grants 2014/09455-3 and 2014/26330-0. G.A.P. acknowledges support from NSF grant EAR-1521534. Seismic waveforms used in this study are freely available from the server of the Seismological Center of the University of São Paulo at http:// sismo.iag.usp.br/rq. All figures were produced with software GMT [Wessel, 1998].
In conclusion, the spectral ratios method proved to be reliable and stable for the computation of earthquake source parameters of colocated small $\left(M_{w}<2\right)$ magnitude earthquakes. In particular, computed seismic moments are very stable and well resolved as shown by the statistic tests and the waveform moment tensor inversions. We found low absolute stress drop values $(<1 \mathrm{MPa})$ and a positive correlation between static stress drop and earthquake size for the studied moment range $\left(M_{w}-0.3\right.$ to 1.9). We propose repeated rupture on a fault patch at shallow depth, following continuous inflow of water, as the cause for the observed low stress drop values and earthquake size dependency. Our study suggests that source parameter characterization may provide additional information of induced seismicity by hydraulic stimulation.

\section{References}

Abercrombie, R. E. (1995), Earthquake source scaling relationships from - 1 to $5 \mathrm{M}_{\mathrm{L}}$ using seismograms recorded at 2.5-km depth, J. Geophys. Res., 100, 24,015-24,036, doi:10.1029/95JB02397.

Abercrombie, R. E. (2014), Stress drops of repeating earthquakes on the San Andreas Fault at Parkfield, Geophys. Res. Lett., 41, 8784-8791, doi:10.1002/2014GL062079.

Abercrombie, R. E. (2015), Investigating uncertainties in empirical Green's function analysis of earthquake source parameters, J. Geophys. Res. Solid Earth, 120, 4263-4277, doi:10.1002/2015JB011984.

Abercrombie, R. E., and J. R. Rice (2005), Can observations of earthquake scaling constrain slip weakening?, Geophys. J. Int., 162(2), 406-424.

Agurto-Detzel, H., M. Assumpção, C. Ciardelli, D. F. Albuquerque, L. V. Barros, and G. S. França (2015), The 2012-2013 Montes Claros earthquake series in the São Francisco Craton, Brazil: New evidence for non-uniform intraplate stresses in mid-plate South America, Geophys. J. Int., 200(1), 216-226.

Allmann, B. P., and P. M. Shearer (2009), Global variations of stress drop for moderate to large earthquakes, J. Geophys. Res., 114, B01310, doi:10.1029/2009JB005821.

Assumpção, M. (1983), A regional magnitude scale for Brazil, Bull. Seismol. Soc. Am., 73(1), 237-246.

Assumpção, M., T. H. Yamabe, J. R. Barbosa, V. Hamza, A. E. Lopes, L. Balancin, and M. B. Bianchi (2010), Seismic activity triggered by water wells in the Paraná Basin, Brazil, Water Resour. Res., 46, W07527, doi:10.1029/2009WR008048.

Baltay, A., S. Ide, G. Prieto, and G. Beroza (2011), Variability in earthquake stress drop and apparent stress, Geophys. Res. Lett., 38, L06303, doi:10.1029/2011GL046698.

Barnhart, W. D., H. M. Benz, G. P. Hayes, J. L. Rubinstein, and E. Bergman (2014), Seismological and geodetic constraints on the 2011 Mw5. 3 Trinidad, Colorado earthquake and induced deformation in the Raton Basin, J. Geophys. Res. Solid Earth, 119, 7923-7933, doi:10.1002/ 2014JB011227.

Boatwright, J. (1980), A spectral theory for circular seismic sources; simple estimates of source dimension, dynamic stress drop, and radiated seismic energy, Bull. Seismol. Soc. Am., 70(1), 1-27.

Brune, J. N. (1970), Tectonic stress and the spectra of seismic shear waves from earthquakes, J. Geophys. Res., 75(26), 4997-5009(Correction, J. Geophys. Res., 76, 5002, 1971), doi:10.1029/JB075i026p04997.

Cotton, F., R. Archuleta, and M. Causse (2013), What is sigma of the stress drop?, Seismol. Res. Lett., 84(1), 42-48.

Dicelis, G., M. Assumpcao, H. Agurto Detzel, R. L. Prado, and J. R. Barbosa (2013), Relocated events in Bebedouro, Paraná Basin, Brazil, confirms they were induced by water wells, Abstract presented at 2013 Fall Meeting, AGU, San Francisco, Calif.

Drouet, S., and M. Assumpção (2013), Spectral analysis of Brazilian data and comparison with ground-motion models, in Proceedings of the 13th International Congress of the Brazilian Geophysical Society, pp. 26-29, Rio de Janeiro.

Drouet, S., M. P. Bouin, and F. Cotton (2011), New moment magnitude scale, evidence of stress drop magnitude scaling and stochastic ground motion model for the French West Indies, Geophys. J. Int., 187(3), 1625-1644.

Duputel, Z., V. C. Tsai, L. Rivera, and H. Kanamori (2013), Using centroid time-delays to characterize source durations and identify earthquakes with unique characteristics, Earth Planet. Sci. Lett., 374, 92-100.

Eshelby, J. D. (1957), The determination of the elastic field of an ellipsoidal inclusion, and related problems, in Proceedings of the Royal Society of London A: Mathematical, Physical and Engineering Sciences, vol. 241, No. 1226, pp. 376-396, The Royal Society, London, U. K.

Garcia-Aristizabal, A., M. Caciagli, and J. Selva (2016), Considering uncertainties in the determination of earthquake source parameters from seismic spectra, Geophys. J. Int., 207(2), 691-701.

Goertz-Allmann, B. P., A. Goertz, and S. Wiemer (2011), Stress drop variations of induced earthquakes at the Basel geothermal site, Geophys. Res. Lett., 38, L09308, doi:10.1029/2011GL047498.

$\mathrm{Gu}, \mathrm{Y}$., and T. F. Wong (1991), Effects of loading velocity, stiffness, and inertia on the dynamics of a single degree of freedom spring-slider system, J. Geophys. Res., 96(B13), 21,677-21,691, doi:10.1029/91JB02271.

Hanks, T., and H. Kanamori (1979), A magnitude moment scale, J. Geophys. Res., 84, 2348-2351, doi:10.1029/JB084iB05p02348.

Hanks, T. C., and M. Wyss (1972), The use of body-wave spectra in the determination of seismic-source parameters, Bull. Seismol. Soc. Am., 62(2), 561-589.

He, C., T. F. Wong, and N. M. Beeler (2003), Scaling of stress drop with recurrence interval and loading velocity for laboratory-derived fault strength relations, J. Geophys. Res., 108(B1), 2037, doi:10.1029/2002JB001890.

Hough, S. E. (1997), Empirical Green's function analysis: Taking the next step, J. Geophys. Res., 102(B3), 5369-5384.

Hough, S. E. (2014), Shaking from injection-induced earthquakes in the central and eastern United States, Bull. Seismol. Soc. Am., 104(5), 1-8.

Huang, Y., G. C. Beroza, and W. L. Ellsworth (2016), Stress drop estimates of potentially induced earthquakes in the Guy-Greenbrier sequence, J. Geophys. Res. Solid Earth, 121, 6597-6607, doi:10.1002/2016jb013067.

Ide, S., and G. C. Beroza (2001), Does apparent stress vary with earthquake size, Geophys. Res. Lett., 28(17), 3349-3352, doi:10.1029/ $2001 \mathrm{GL} 013106$.

Ide, S., G. C. Beroza, S. G. Prejean, and W. L. Ellsworth (2003), Apparent break in earthquake scaling due to path and site effects on deep borehole recordings, J. Geophys. Res., 108(B5), 2271, doi:10.1029/2001JB001617.

Kane, D. L., G. A. Prieto, F. L. Vernon, and P. M. Shearer (2011), Quantifying seismic source parameter uncertainties, Bull. Seismol. Soc. Am., 101(2), 535-543.

Kissling, E., W. L. Ellsworth, D. Eberhart-Phillips, and U. Kradolfer (1994), Initial reference models in local earthquake tomography, J. Geophys. Res., 99(B10), 19,635-19,646, doi:10.1029/93JB03138. 
Kwiatek, G., and Y. Ben-Zion (2013), Assessment of $P$ and $S$ wave energy radiated from very small shear-tensile seismic events in a deep South African mine, J. Geophys. Res. Solid Earth, 118, 3630-3641, doi:10.1002/jgrb.50274.

Kwiatek, G., and Y. Ben-Zion (2016), Theoretical limits on detection and analysis of small earthquakes, J. Geophys. Res. Solid Earth, 121, 5898-5916, doi:10.1002/2016JB012908.

Lengliné, O., L. Lamourette, L. Vivin, N. Cuenot, and J. Schmittbuhl (2014), Fluid-induced earthquakes with variable stress drop, J. Geophys. Res. Solid Earth, 119, 8900-8913, doi:10.1002/2014JB011282.

Lin, Y. Y., K. F. Ma, H. Kanamori, T. R. A. Song, N. Lapusta, and V. C. Tsai (2016), Evidence for non-self-similarity of microearthquakes recorded at a Taiwan borehole seismometer array, Geophys. J. Int., 206(2), 757-773.

Mayeda, K., and W. R. Walter (1996), Moment, energy, stress drop, and source spectra of western United States earthquakes from regional coda envelopes, J. Geophys. Res., 101(B5), 11,195-11,208, doi:10.1029/96JB00112.

Nuttli, O. W. (1983), Average seismic source-parameter relations for mid-plate earthquakes, Bull. Seismol. Soc. Am., 73(2), 519-535.

Prieto, G. A., P. M. Shearer, F. L. Vernon, and D. Kilb (2004), Earthquake source scaling and self-similarity estimation from stacking $P$ and $S$ spectra, J. Geophys. Res., 109, B08310, doi:10.1029/2004JB003084.

Prieto, G. A., R. L. Parker, F. L. Vernon, P. M. Shearer, and D. J. Thomson (2006), Uncertainties in earthquake source spectrum estimation using empirical Green functions, in Earthquakes: Radiated Energy and the Physics of Faulting, pp. 69-74, Washington, D. C.

Prieto, G. A., D. J. Thomson, F. L. Vernon, P. M. Shearer, and R. L. Parker (2007), Confidence intervals for earthquake source parameters, Geophys. J. Int., 168(3), 1227-1234.

Prieto, G. A., R. L. Parker, and F. L. Vernon III (2009), A Fortran 90 library for multitaper spectrum analysis, Comput. Geosci., 35(8), 1701-1710.

Ross, Z. E., and Y. Ben-Zion (2016), Toward reliable automated estimates of earthquake source properties from body wave spectra, J. Geophys. Res. Solid Earth, 121, 4390-4407, doi:10.1002/2016JB013003.

Rubin, A. M., and J. P. Ampuero (2005), Earthquake nucleation on (aging) rate and state faults, J. Geophys. Res., 110, B11312, doi:10.1029/ 2005JB003686.

Rubinstein, J. L., and A. B. Mahani (2015), Myths and facts on wastewater injection, hydraulic fracturing, enhanced oil recovery, and induced seismicity, Seismol. Res. Lett., 86(4), 1060-1067.

Rubinstein, J. L., W. L. Ellsworth, A. McGarr, and H. M. Benz (2014), The 2001-present induced earthquake sequence in the Raton Basin of northern New Mexico and southern Colorado, Bull. Seismol. Soc. Am., 104, 2162-2181.

Shearer, P. M. (2009), Introduction to Seismology, Cambridge Univ. Press, Cambridge, U. K.

Shearer, P. M., G. A. Prieto, and E. Hauksson (2006), Comprehensive analysis of earthquake source spectra in Southern California, J. Geophys. Res., 111, B06303, doi:10.1029/2005JB003979.

Sokos, E., and J. Zahradník (2013), Evaluating centroid-moment-tensor uncertainty in the new version of ISOLA software, Seismol. Res. Lett., 84(4), 656-665.

Sokos, E. N., and J. Zahradnik (2008), ISOLA a Fortran code and a Matlab GUI to perform multiple-point source inversion of seismic data, Comput. Geosci., 34(8), 967-977.

Wells, D. L., and K. J. Coppersmith (1994), New empirical relationships among magnitude, rupture length, rupture width, rupture area, and surface displacement, Bull. Seismol. Soc. Am., 84(4), 974-1002.

Wessel, P. (1998), New, improved version of Generic Mapping Tools released, Eos. Trans. AGU, 79, 579, doi:10.1029/98EO00426.

Zahradník, J., and F. Gallovič (2010), Toward understanding slip inversion uncertainty and artifacts, J. Geophys. Res., 115, B09310, doi:10.1029/ 2010JB007414.

Zhan, Z., D. V. Helmberger, H. Kanamori, and P. M. Shearer (2014), Supershear rupture in a Mw 6.7 aftershock of the 2013 Sea of Okhotsk earthquake, Science, 345(6193), 204-207.

\section{Erratum}

In the originally published version of this article, there was a typesetting error in equation 5 in which $\pi$ was set as $p$. The equation has since been corrected, and this version may be considered the authoritative version of record. 